Revista Iberoamericana, Vol. LXVIII, Núm. 200, Julio-Septiembre 2002, 591-592

\title{
MI DEUDA CON BALDOMERO SANÍN CANO
}

POR

JoAquín García Monge

Con estos renglones correspondo a la benévola y honrosa invitación que me ha hecho el profesor Manuel Pedro González, en Los Ángeles, California. No sabe cómo se la agradezco.

Se trata de pagarle al insigne maestro Sanín Cano el tributo de respeto y gratitud que le debemos, hace años, los americanos instruidos del centro y del sur. Ojalá este homenaje sea para el prócer, en su modestia, motivo de bienestar y alegría. Y que su caso extraordinario sirva de ejemplo y estímulo a las generaciones nuevas. Cuánto tienen ellas que aprender en la vida larga y en la maciza obra literaria de Sanín Cano. Su perdurable lealtad consigo mismo. Su señorío espiritual inalterable.

Como editor del Repertorio Americano cuánto le debo, cuánto he recogido para bien de todos, de su valiosa cosecha de comentarista en La Nación de Buenos Aires, en El Tiempo de Bogotá. Saco la cuenta y veo complacido que en el Repertorio Americano se han reproducido 155 artículos de Sanín Cano. Y cuántos más esperan la ocasión favorable, o ya habrían salido, si de 1936 a la fecha no hubiese perdido el paso de semanario que hasta entonces traía. No sé de otra revista hispanoamericana que haya hecho lo mismo con su producción de publicista, sustento y sostén de generaciones. (Ciencia y conciencia). Se le recordará con el tiempo como sembrador empeñoso, uno de los padres de hombres de nuestra América, junto a Bello, Sarmiento, Luz y Caballero, Cecilio Acosta, Hostos, Martí, para citar algunos.

Un plan, un ideario rico, renovado sin cesar, muchas lecturas y meditaciones, sin egoísmos ni vanidades, sin retóricas ni alardes, con sentido de la patria, como empresa de cultura, constancia y fe creadora; tal es, en conjunto, lo que nos ha dado Sanín Cano como periodista en 50 años.

En enero de 1913, en el epítome número 25 de la Colección Ariel, lo presenté a los lectores costarricenses como "excelente escritor colombiano" y reproduje el primer artículo suyo, titulado "La Universidad y el espíritu nuevo"; lo saqué de Hispania, Londres, noviembre $1^{\circ}$ de 1912.

Buscar el espíritu nuevo, en todas direcciones; tal ha sido uno de los más fecundos propósitos de Sanín Cano publicista. Cogió a tiempo la brújula y sabe a dónde va y cómo se va y marca luego a los hispanoamericanos el rumbo acertado. Es deplorable que la escasa difusión y coordinación de las ideas en que aún vivimos, no haya contribuido lo 
bastante a que sea más leído y reflexionado. En esta salvadora federación de ideas hispanoamericanas con que soñamos hace años, Sanín Cano sería uno de los promotores constructivos.

En el Repertorio Americano del 6 de diciembre de 1947 hemos recogido el artículo de Sanín Cano: “Diarios en la escuela y escritores sin diario”. Es de diciembre de 1946 y lo tomamos de El Tiempo de Bogotá.

Es muy significativo: en ambos artículos, el primero y el último, a distancia de 34 años, una preocupación docente, como del rector que siempre ha sido Sanín Cano.

Y si nos fuera posible examinar, una a una, las 155 reproducciones a que antes me referí, y correlacionarlas, se vería que dentro del Repertorio Americano han seguido un rumbo, de acuerdo con el pulso que por años la revista le ha venido tomando a la conciencia de nuestra América. El crítico literario, el humorista, el estadista, el americano preocupado que hay en Sanín Cano, en esos 155 ensayos se manifiesta y de qué modo. Las nuevas tendencias económicas, políticas, literarias, filosóficas, educativas ..., el libro nuevo, de ciencias o letras, el autor, de aquí o de allá, Sanín Cano los señala y da el consejo. Es un guía inmejorable, curioso, previsor, con el corazón y la inteligencia puestos en su Colombia, en su América.

Acérquense a Sanín Cano los jóvenes estudiosos, los periodistas nuevos; es saludable su influencia. Yo lo hallé por ahí de 1913, o tal vez antes, y desde entonces somos amigos, y he seguido sus pasos luminosos de egregio propulsor de cultura. Mucho estimo y quiero a Sanín Cano. Mucho tengo que agradecerle. La primera que busco y leo, en las entregas de El Tiempo que afortunadamente recibo, es la del lunes, la que trae el último y esperado artículo de Sanín Cano.

Lo vuelvo a leer al cabo de los años y hallo sus escritos tan sabrosos como antes.

De los escasos ciudadanos del mundo y compatriotas del hombre que en nuestra América tenemos, Sanín Cano es uno de ellos. Otros han de hablar en este homenaje de su calidad de escritor: pulcritud, sobriedad y elegancia en el decir: sencillo, claro: no les teme a las ideas, todas le interesan, las estudia, y se empeña en comprenderlas: su castellano aprendido tan a fondo, la gramática, la sabiduría del idioma propio y la de los ajenos: cuánto nos da, oportuno, de su saber copioso en historia, ciencias, filosofía y letras, de su rico anecdotario. Un pensamiento liberal, sin estridencias ni excomuniones. Disciplina, ecuanimidad y ponderación. Saber útil el suyo, bondad útil también diríamos. En eso se ha vivido. 